\title{
Evolution of Corporate Marketing Model: Based on the Era of Big Data
}

\author{
J. ZHAO, J. HE, F. YU, G. H. ZHAN \\ College of liren, Yanshan University, Qinhuangdao, Hebei, China
}

\begin{abstract}
Corporate marketing is being supplied broader marketing channels and advertising space in the background of Big Data. Meanwhile under the age of big data environment the complexity and uncontrollability of enterprise marketing environment is increased. By defining the nature and characteristics of big data, and then analyzing the plight thatcorporate marketing faced under the background of big data, and to build a big enterprise marketing system in order to improve the level and quality of corporate marketing efficiency.
\end{abstract}

KEYWORD: Corporate Marketing; Big Data; Evolution

\section{INTRODUCTION}

In addition to Cloud Computing and the Internet of Things, information technology industry in recent years and created a new phrase - the Big Data, became the "Cloud Computing" and "Internet of Things" after the key elements of the impact on various aspects of social life. For marketing management, it is the combination of science and art, in selecting target markets, on the basis of value creation, spread value, to deliver high quality value, and favored by the customers. And for marketing and advertising, the role of big data is becoming more and more important, at the same time of deconstruction of traditional marketing system, reconstruct the new marketing system. "Scientific" mainly embodies in for marketing part of the established marketing rely on database, data collection and analysis. The whole process of marketing system and always runs through the use of big data, it is vital for marketing effect. In this article, will focus on in the background of big data, marketing system is how to carry out the deconstruction and reconstruction, and the formation of the existence of trend and internal logic.

\section{THE NATURE AND CHARACTERISTICS OF THE BIG DATA}

\subsection{The nature of the big data}

Mirror worlds are physical virtual map of the world, the image is like a mirror, and the real world itself still has the nature of expression and association. So to see big data based on this concept, see its corresponding category essence is "mirror world", or you can think that big data is a process, refers to the human science and technology has been achieved can start to work in the "mirror" phase. however, the concept of "big data" makes people focus on the image data, and ignore the essential fact that big data reflect the social phenomenon fundamentally is a kind of extension and human existence paradigm shift, that is, from a single material, the survival of materialization into materialization, materialization survival and mutual fusion comprehensive "mirror" the survival way of life. Big data under the background of "mirror" survival is the use of computers and the Internet and communications equipment such as hardware, with data to show the material world and its operation process of real existence of various relationships. As customers can through the Internet, using the keyboard, mouse and other hardware can replace the traditional shopping behavior, and this kind of behavior can be seen as a mirror for the shopping process. The internal logic relationship of deep didn't change, just like a car need to pay and sell cars need shipment, but realize this business relationship, however, there has been a fundamental change. 


\subsection{The characteristics of the big data}

Table 1 The nature of big data segment

\begin{tabular}{|c|c|c|}
\hline \multirow{7}{*}{$\begin{array}{l}\text { BIG } \\
\text { DATE }\end{array}$} & The characteristics & $\begin{array}{l}\text { Refinement and Detailed } \\
\text { rules }\end{array}$ \\
\hline & \multirow{2}{*}{ Volume } & The number \\
\hline & & Simulacra of ontology level \\
\hline & \multirow{2}{*}{ Variety } & Structure data \\
\hline & & Unstructured data \\
\hline & \multirow[t]{2}{*}{ Velociay } & $\begin{array}{l}\text { Information has the validity } \\
\text { between main body and the } \\
\text { real world }\end{array}$ \\
\hline & & Network real value \\
\hline
\end{tabular}

The first is Volume - to be false. Big data Volume too big to know their edge. The so-called Volume is not only a quantitative concept, is essentially a qualitative concept. The reason is that from the perspective of image change survival, big data is Volume, the characteristics of the initial reflected in the mirror for high and low degree of simulacra of ontology, data is only reached the critical value of the most basic, there is a possibility of material entity world become something of a mirror. Volume, in other words, this standard is not just a simple sense of the Numbers, but can digital image can be achieved for the mirror practice for service standards. From the traditional sense of the Very Big Data to the Massive Data to the Big Data, is essentially a digital simulacra from quantitative change to qualitative change a tipping point, and not all simulacra of Data to be able to become a "Big Data", it depends on whether it can serve the mirror practice. The so-called Volume also only then has the relativity quantitatively, rather than absolute.

The second is Variety - more than true enough. The consensus that in today's world, the "big" of the big data but also on its rich variety of types, that is, from the traditional sense of the state of structured data to the structured data and unstructured data exist at the same time. In a sense, this once again shows that the so-called "big data" is still in essence human physical image of the physical world to survive. Because in essence, the human in the real world is a nonlinear relationship between the objective existence of the entity, using structured data like form is part of a special case of the physical world or real substance. As the network world and the human in the real world further, along with the further development of science and technology, in the real world of nonlinear relationship gradually using unstructured data in digital network space mapping, realizes the simulacra cyberspace to the real world.

The third is Velocity - Fast to have limitation. Just as the famous sociologist Gary king said: "these data are valuable, is that they have the time." For material mirror version of the physical world, early if you want to let the network society with the existence of the "virtual world" there's a difference, make it has some degree of practical significance, it must be able to and material physical world synchronization, timely, which means information and data in the image world linked to have the world of timeliness and material entities. Only meet this condition, the mirror world was able to connect with the real world, make its have infinite value. Otherwise, all the simulacra were just don't have the vitality of the "phantom", and will not be able to call it the "mirror image". Only the rapidness, can make the mirror worlds of simulacra and form have vitality, can "live", become people to explore a mirror of the real world. To sum up, the rapidness of the characteristic, is to support the "big data" has the realistic meaning and practical value of the third pillar. Of course, the rapidness is a relative concept. The only standard to judge the rapidness of is this rapid can make between the subject and the real world information is effective, but with the progress of science and technology and the transformation of the people practice demands, the validity of judgment standard changes.

\section{THE DILEMMA THE CORPORATE MARKETING FACED UNDER THE BIG DATA ERA}

The advent of the era of big data produced the shock to the traditional enterprise marketing, changed the traditional marketing mode of enterprise, for enterprise marketing, is a good thing. However, for the enterprise marketing system, with large data, in addition to the change, there are difficulties:

\subsection{More strict privacy and data protection technology}

Big data in bring convenience to people at the same time, also has brought the security problems. Network is an open platform, in the network, between people, even the communication and exchanges between the people and things is increasingly close, in the case of multi-agent, will inevitably involve information security and secrecy. A huge amount of information stored in the network users and privacy, if not protected, the information leak out, is likely to produce very big effect to the customer, light person the user information will be exposed to go out, the person that weigh may benefit to the enterprise or individual losses. Combined with advanced network technology makes all kinds of information access devices, such as candid, recording equipment is becoming more and more developed, so the network security problems need to solve. On for privacy information and the protection of user interests, the eu has made a beneficial try, 
they are widely carried out discussion of user information protection, the discussion not only involves the technical aspects, also involves the legal aspects, and puts forward the guiding principle of the privacy protection and good results have been achieved.

\subsection{Technology standard is not perfect and application of the high cost}

There is no denying the fact that as the development of the world's most new information technology, the prospects for big data is very wide, but its development is some twists and turns, reason is that at present the relevant technology of the big data standard is not perfect enough, the use of big data has a high cost. The first incomplete technical standards, do not have a unified coding standard. At present the relevant goods barcode has multiple writing way, enterprises are faced with the choice dilemma, so the encoding of diversification and the establishment of a unified product information query platform becomes more difficult, solve these problems. Another technology is not mature, also let enterprise has a high cost of popularization and application. Big data applications involve enterprise invested a lot of money, no doubt increased the operating costs. According to the above problem, the government and enterprises to jointly create a big data and RFID application demonstration bases, such as Shanghai zhangjiang RFID demonstration center is very representative. At present, Shanghai zhangjiang in big data technology research and development, which are go-ahead, standards, etc, has a group of independent innovation ability of high-end research and development of enterprises and institutions, about 500 gathered large data related enterprises, has formed billions of yuan of industrial scale.

\subsection{Industry chain is longer, involves more technology}

Big data technology has a long industrial chain, and it involves a lot of integration architecture, and so he involve more technical means, such as nanotechnology, information network communication technology, sensor technology, etc., have higher request for these technologies. Even under the background of big data industry and traditional industry chain has the same or similar part, but also have different, big data in the upper part of the industrial chain add sensor technology and RFID technology(these two technologies can give it to the products of unique identity authentication information, and can realize intelligent cognitive), on the downstream of the industry chain to increase large data carriers, it can provide abundant information for the user and analyze the information processing). Therefore, the enterprise marketing mode should make full use of big data, need to have a very mature technology, but technology is not mature at present stage, which is under the background of big data, one of the difficulties faced by developing new marketing pattern.

\subsection{Abstract Demanding higher precision, peripheral interface support is required}

Because of big data is mainly used in industrial conditions, its working environment may not be very good, so the MCU (micro control unit) have higher requirements, such as its stability is higher, and lower energy consumption as far as possible, and interference resistance. Big data has a higher demand on the micro control unit, because it is the information analysis and processing, the requirement to the nodes with high intelligent. Big data and previous independent electrical appliances product also is not the same, he need related industry chain to provide support, so the high performance requirements of micro control unit, but also need the support of relevant peripheral interface. Besides big data is based on the sensor nodes and the network applications, the sensor type very much, now the core issue is accuracy, the accuracy for the enterprise product sales. Such as blood pressure, need to follow the standard manual operation, to accurately measure blood pressure. But under the large data of sensor is not so stable, is strongly influenced by the environment, for example, in the high temperature or the elegant environment, the sensor will be affected, and even failures, which restrict the sale of the products.

\section{CONSTRUCTION STUDY OF THE CORPORATE MARKETING SYSTEM UNDER BIG DATA ERA}

With the integration of enterprise to the upstream enterprises and the transformation of the terminal, at the same time also brought the whole transformation of industrial structure, change the traditional information resources input and output mechanism. In addition, also make network drew a large audience, as users, information resource become more abundant, the spread of the breadth and depth greatly increased, the transmission speed has been greatly improved, therefore, due to the advent of the era of big data, the enterprise marketing system was reconstructed, realize the whole media marketing is no longer the imagination. To build the system of media marketing, there are two big essential factors, and must first have a storage have rich information resource database, secondly also need an effective information communication platform. Relying on these two elements, big data to the user information 
to conduct a comprehensive and detailed analysis, and classifying users, targeted marketing, improve the success rate of the marketing for the enterprise to provide more profitable.

\subsection{Building enterprise marketing big data information platform, data information and marketing of matches}

Big data in the change of traditional enterprise marketing chain, expand information circulation, youdao audience to change their behavior, etc, has important significance. And in the research field of the latest information platform, big data can play its important role. This new may mainly embodied in four aspects: The first is the increased amount of data has achieved the conversion from quantitative change to qualitative change; Second, under the background of big data, through the data record the end user will all the actions and information is recorded and preserved, as a result of these records is done through a vast Internet, information collection channels, large amount of information, the resulting database is the most real, the most comprehensive; Third, bring the mature technology of big data and reduce the cost of access to information; Fourth, big data is open to all users, all the audience are able to release information, thus has strong interactivity.

The so-called information platform, is refers to a large number of rich data between the means of circulation, and the transmission of the platform, at present, the personal information platform and information platform of the preliminary construction family has made certain research results. Big data under the background of marketing system, the main purpose of the information platform is: will collect relevant data analysis, provide a reference for marketing work in the future. After these through scientific analysis and processing of information, can reflect the consumer demand and consumption orientation, to understand the consumer psychology of consumers of enterprise nature is able to make targeted marketing plan, thus raised the probability of successful marketing. Personal information platform of the working mechanism and the description is the same. Just a marketing plan for individual target rules. Personal information platform mainly through individual user's individual media terminal to consumer behavior and consumer information the user to record and grade, and analyzed, and then analyzed the information sent to the enterprise to provide customers with the products or services and is responsible for product marketing and promotional agencies, these institutions according to the information they receive targeted again, in a planned way consumer advertising, cater to consumer tastes and consumer psychology, so as to improve the success rate of the marketing. In addition, the community information service platform is also similar, "community" in the community service platform, not only from the network sense, including the "community" in real life. Big data under the background of the media marketing, its value is mainly manifested in the three major information platform (individuals, businesses, and community information platform) and the application of marketing.

\subsection{Data and information to transition to the data products}

On the one hand, the era of big data change the traditional marketing model and marketing system; Big data, on the other hand, also makes the marketing to enhance the success rate; At the same time, big data has given rise to a new profit model -data already is not only a kind of information, it has become one kind of product, can bring benefits. Information platform of rich user information after a big data collection technology, it has a very high commercial value, become a "data" products, sales. In the case of Taobao, Taobao has its own cloud Ocean Base, the system holds rich trading data, through the system, Taobao success to realize the change of the data to the data products. Analyzed by collecting a large number of rich data, Taobao has now developed a variety of product data, these data products can not only provide service for Taobao sellers, can also serve other businesses except Taobao, can offer all kinds of web sites and community social electricity business solutions, can provide all kinds of optimization tools for Taobao sellers, can provide customers with all kinds of optimization tools. Since the data is a description of consumer demand, so the new business model will be followed by a communication (through data analysis) and consumer demand of the construction of the bridge between sales and appear.

\section{REFERENCES}

[1] G. Oggioni, Y. Smeers. Market failures of Market Coupling and counter-trading in Europe: An illustrative model based discussion. Energy Economics, 2013, Vol35, pp. 74-87.

[2] Álvaro Capitán Herráiz, Carlos Rodríguez Monroy. Analysis of the traded volume drivers of the Iberian power futures market. International Journal of Electrical Power and Energy Systems, 2013, Vol44, pp. 431-440.

[3] Tang Mun Bbun, Alec Thornton. A level playing field? Improving market availability and access for small scale producers in Johannesburg, South Africa. Applied Geography, 2013, Volume 36, January 2013, pp. 40-48.

[4] Imam Wahyudi, Gandhi Anwar Sani. Interdependence between Islamic capital market and money market: Evidence from Indonesia. Borsa istanbul Review, 2014, Vol14, pp. 32-47. 